Xiangmeng Meng, Marcel Bachmann, Antoni Artinov, Michael Rethmeier

\title{
Experimental and numerical assessment of weld pool behavior and final microstructure in wire feed laser beam welding with electromagnetic stirring
}

Journal article | Accepted manuscript (Postprint)

This version is available at https://doi.org/10.14279/depositonce-10545

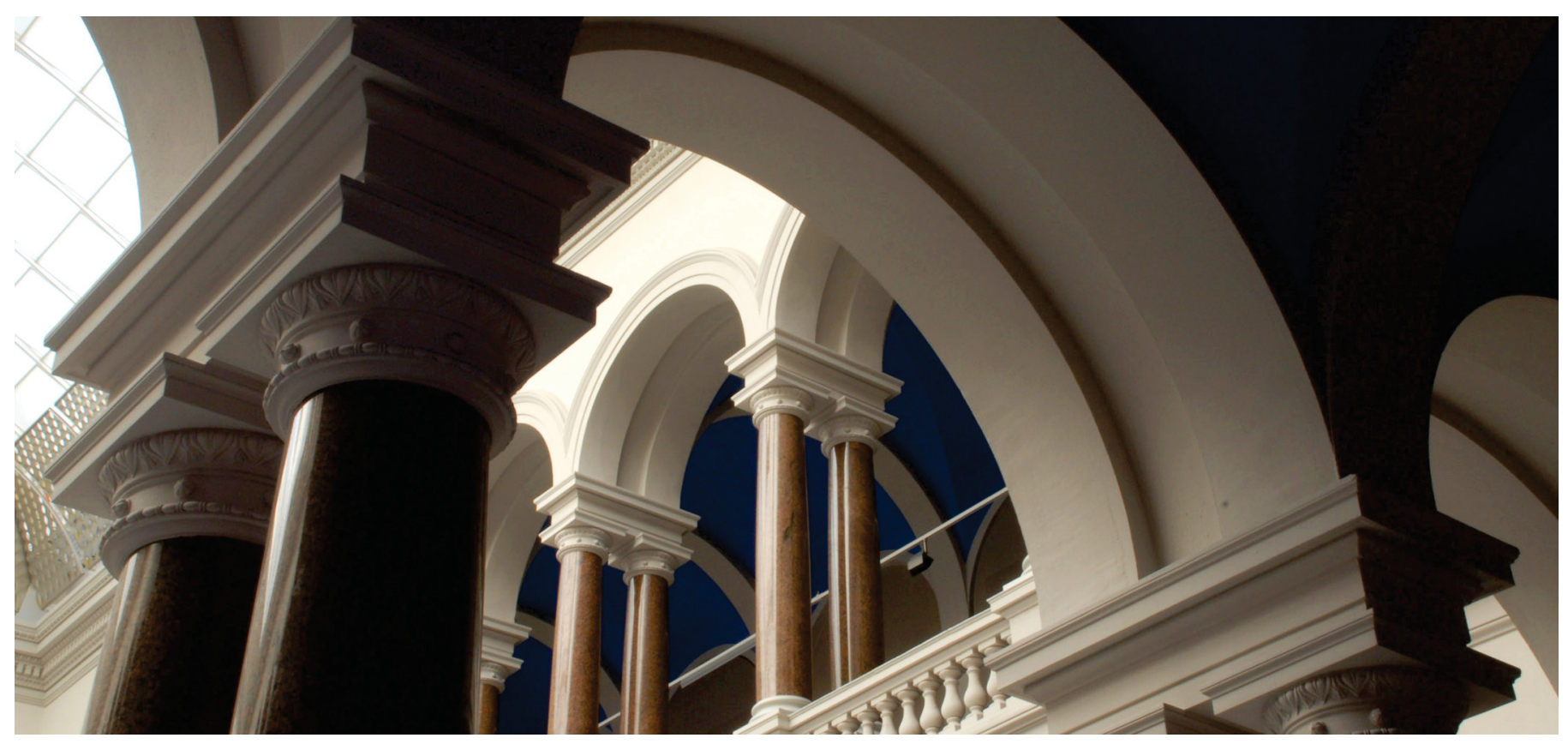

Meng, Xiangmeng; Bachmann, Marcel; Artinov, Antoni; Rethmeier, Michael (2019). Experimental and numerical assessment of weld pool behavior and final microstructure in wire feed laser beam welding with electromagnetic stirring. Journal of Manufacturing Processes, 45, 408-418.

https://doi.org/10.1016/j.jmapro.2019.07.021. 


\title{
Experimental and numerical assessment of weld pool behavior and final
} microstructure in wire feed laser beam welding with electromagnetic stirring

\author{
Xiangmeng Meng ${ }^{\mathrm{a}, *}$, Marcel Bachmann ${ }^{\mathrm{a}}$, Antoni Artinov ${ }^{\mathrm{a}}$, Michael Rethmeier ${ }^{\mathrm{a}, \mathrm{b}}$ \\ a BAM Federal Institute for Materials Research and Testing, Unter den Eichen 87, 12205 Berlin, Germany \\ b Technical University Berlin, Institute of Machine Tools and Factory Management, Pascalstraße 8-9, 10587 \\ Berlin, Germany \\ Corresponding author: xiangmeng.meng@bam.de
}

\begin{abstract}
Advantages such as element homogenization and grain refinement can be realized by introducing electromagnetic stirring into laser beam welding. However, the involved weld pool behavior and its direct role on determining the final microstructure have not been revealed quantitatively. In this paper, a 3D transient heat transfer and fluid flow model coupled with element transport and magnetic induction is developed for wire feed laser beam welding with electromagnetic stirring. The magnetohydrodynamics, temperature profile, velocity field, keyhole evolution and element distribution are calculated and analyzed. The model is well tested against the experimental results. It is suggested that a significant electromagnetic stirring can be produced in the weld pool by the induced Lorentz force under suitable electromagnetic parameters, and it shows important influences on the thermal fluid flow and the solidification parameter. The forward and downward flow along the longitudinal plane of the weld pool is enhanced, which can bring the additional filler wire material to the root of the weld pool. The integrated thermal and mechanical impacts of electromagnetic stirring on grain refinement which is confirmed experimentally by electron backscatter diffraction analysis are decoupled using the calculated solidification parameters and a criterion of dendrite fragmentation.
\end{abstract}

Keywords: Magnetohydrodynamics; weld pool behavior; grain structure; laser beam welding; numerical simulation

\section{Introduction}

The availability of high-power laser sources makes the laser beam welding (LBW) performed in deep penetration mode (keyhole mode) become one of the most promising metal joining processes in modern manufacturing industry, e. g. aerospace, ship-building and large high-pressure or vacuum 
vessels. In comparison to conventional arc welding, the LBW has well-known advantages such as good penetration capacity, low heat input, high reachable welding speed, narrow heat affected zone (HAZ) and low welding distortion. The use of filler wire in LBW, namely wire feed LBW (WFLBW), brings further advantages: (i) better capacity of gap bridging, (ii) improvement of metallurgical properties by adding suitable chemical composition through additional filler material, (iii) possibility to fulfill heavy section welding by multi-pass technique [1]. However, there are still challenges in WFLBW making the realization of the advantages difficult, especially for thick plate welding. The additional elements from filler wire can hardly be distributed homogeneously in the final weld due to the high cooling rate of weld pool (up to $1 \times 10^{6} \mathrm{~K} / \mathrm{s}$ ) [2]. They mainly concentrate at the upper part of weld, which may deteriorate the homogeneity of the resultant property.

The electromagnetic control which is a contactless technique provides a possible way to solve the issues occurring in the WFLBW process. The magnetohydrodynamics (MHD) theory shows that a current density will be induced if an external magnetic filed is applied to flowing electrically conducting material, for example liquid metal [3]. A volumetric Lorentz force will be generated by the magnetic field and its induced current. By choosing a proper external magnetic field, supporting, deceleration or stirring can be produced to control the weld pool behavior.

The positive effect of a magnetic field (e.g. flow control and grain structure refinement) in material processing has been well accepted, especially for the casting [4]. Kern et al. first found that the humping defect in high-speed LBW was eliminated by the external magnetic field because the strong backward flow of liquid metal was decelerated under the Lorentz force [5]. The oscillating magnetic field was used by Avilov et al. to provide effective support against the gravity, and thereby, the root sagging in the full penetration LBW was suppressed [6]. The work of Fritzsche et al. suggested that the high-frequency oscillating magnetic field at transverse direction made a dramatical reduction of process porosity in the partial penetration LBW of Aluminium [7]. Gatzen employed a low-frequency coaxial alternating magnetic field to enhance the material mixing in the weld pool of WFLBW. A more homogeneous distribution of Si from the filler wire in the resultant weld was obtained because of the electromagnetic stirring [8]. The magnetic field also showed beneficial effects on the improvement of microstructure, for example refinement of grain structure in the laser + arc hybrid welding of austenitic steel steel [9] and suppression of brittle intermetallic compounds in the laser welding of steel to Aluminium [10].

The thermal process and liquid flow in the weld pool play an important role on determining the weld geometry, element distribution and solidification microstructure. Integrated and quantitative description of the weld pool behavior is necessary to provide a deeper insight of the physical 
mechanism of LBW with magnetic field. Some experimental investigations e. g. high-speed imaging with quartz glass [11] or microfocused X-ray transmission with tracer particles [12], have been conducted. However, quantitative experimental characterization of the thermophysical information in the weld pool, which varies temporally and spatially, is still an extremely difficult task because of the intensive light of the laser induced plasma, the small dimension of the weld pool and the nontransparent nature of the liquid metal.

Some multi-physical modelling works have been conducted to study the physical relationship between the weld pool behavior and applied magnetic field in LBW. A three-dimensional steady-state numerical model was developed by Bachmann et al. to calculate the MHD behavior and thermal fluid flow in the weld pool of LBW with external magnetic field [13, 14]. The thermoelectric-magnetic phenomena in a full penetration LBW of aluminum with steady magnetic support was investigated using a steady-state numerical model, and it was found that the thermoelectric current caused by Seebeck effect showed a non-negligible influence on the material flow and weld morphology [15]. Gatzen et al. studied the influence of coaxial magnetic field on the liquid flow and the final element distribution in WFLBW numerically. The mixing of additional element in the weld pool was enhanced by the electromagnetic stirring [16]. Although a few of numerical works have been reported, a fixed keyhole surface whose temperature was set as the boiling point of material was used in most of these models. They failed to consider the important impact of dynamic keyhole evolution. Lately, Chen et al. used a numerical LBW model with dynamic keyhole to study the influence of thermoelectric force from a steady magnetic field on the weld microstructure [17].

The influence of magnetic field on the weld pool behavior in LBW is still not clear. Furthermore, the direct role of crucial physical phenomena, such as temperature gradient, solidification rate and mechanical fragmentation, on determining the final microstructure in the LBW with magnetic field has not been discussed quantitatively either. This paper provides an experimental and modelling study of WFLBW with electromagnetic stirring (EMS-WFLBW). The induced eddy current, Lorentz force as well as the temperature and velocity profiles, solidification parameters, keyhole evolution and element transport are calculated by a three-dimensional transient multiphysical model. The weld pool behavior in WFLBW and EMS-WFLBW are compared and analysed. The grain structure is rationalized using numerical data and results from optical micrograph (OM) and electron backscatter diffraction (EBSD) analysis.

\section{Materials and experimental methods}

The base metal material is AISI 304 austenitic steel, and the filler material is nickel-based 
Inconel 625 wire. The dimension of base metal is $200 \mathrm{~mm} \times 60 \mathrm{~mm} \times 10 \mathrm{~mm}$, and the diameter of the filler wire is $1.2 \mathrm{~mm}$. Their nominal chemical compositions are given in Table 1. There is a huge difference of Ni content between the base metal and the filler material, so the mixing in the weld pool can be characterized by the distribution of $\mathrm{Ni}$.

A fiber laser system (IPG YLR 20000) was used as the laser source with a wavelength of 1070 $\mathrm{nm}$, a spot diameter of $0.52 \mathrm{~mm}$ and a focal length of $350 \mathrm{~mm}$. Butt configuration with zero gap was performed. The laser power was $7.5 \mathrm{~kW}$, the welding speed was $1.3 \mathrm{~m} / \mathrm{min}$ and the focal plane was 3 $\mathrm{mm}$ below the base metal surface. The cold filler wire was fed in front of the laser spot with $33^{\circ}$ angle with respect to the workpiece, and the wire feeding speed was $2.1 \mathrm{~m} / \mathrm{min}$. The shielding gas of pure Argon was provided behind the laser spot in a flow rate of $201 / \mathrm{min}$. An AC electromagnet was fixed above the base metal and had a $75^{\circ}$ angle with respect to the welding direction, as shown in Fig. 1(a). This configuration was chosen to produce an asymmetric Lorentz force distribution and thus enhance the stirring of molten metal. The cross-section of the core has a dimension of $16 \mathrm{~mm} \times 16 \mathrm{~mm}$, and the distance between two poles are $20 \mathrm{~mm}$. An oscillating magnetic field with a frequency of 3600 $\mathrm{Hz}$ was produced. Before welding, the root-mean-square value of magnetic flux density was measured by a Hall sensor in cold metal condition, as shown in Fig. 1(b).
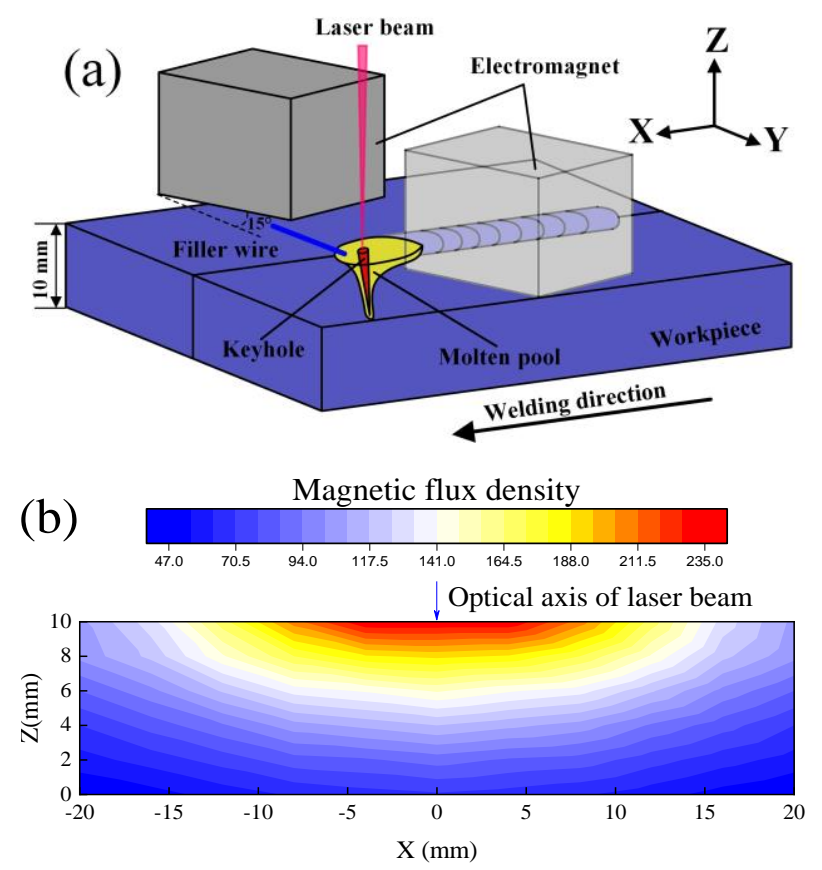

Fig. 1 Experimental system: (a) schematic of EMS-WFLBW, (b) distribution of magnetic flux density. 
Table 1 Nominal chemical composition of 304 steel and Inconel 625

\begin{tabular}{ccccccccc}
\hline Alloy & $\mathrm{Ni}$ & $\mathrm{Cr}$ & $\mathrm{Mo}$ & $\mathrm{Nb}$ & $\mathrm{C}$ & $\mathrm{Si}$ & $\mathrm{S}$ & $\mathrm{Fe}$ \\
\hline 304 steel & $8.0-10.0$ & $17.5-19.0$ & - & - & $<0.07$ & $<0.75$ & $<0.015$ & Bal. \\
Inconel 625 & Bal. & $20.0-23.0$ & $8.0-10.0$ & $3.2-4.2$ & $<0.10$ & $<0.50$ & $<0.015$ & $<5$ \\
\hline
\end{tabular}

A Photron FASTCAM SA4 camera was used to capture the high-speed images of weld pool and filler material transfer with a frequency of 500 frames per second. The distance between the weld pool and the lens was $400 \mathrm{~mm}$. The principal optical axis of the camera was vertical to $\mathrm{X}$-axis (welding direction) and had a $10^{\circ}$ angle with respect to the weld pool (XOY plane). The specimens were grinded and polished mechanically first, and etched by a solution of $100 \mathrm{ml} \mathrm{H}_{2} \mathrm{O}, 100 \mathrm{ml} \mathrm{\textrm {HNO } _ { 3 }}$ and $10 \mathrm{ml} \mathrm{HCl}$ at a temperature of $50{ }^{\circ} \mathrm{C}$ for 30 seconds. Then the fusion line shape on the transverse section of weld was observed by an optical microscope. An EDX line scanning was conducted to measure the Ni content along the center line of the transverse section. The EBSD analysis was performed to measure the grain structure and orientation. The surface of the specimen was treated by electropolishing to ensure that no additional stress was introduced.

\section{Mathematical modelling}

The nomenclatures used are listed in Table 2. Considering the highly non-linear and multicoupled phenomena occurring in the EMS-WFLBW, several key simplifications are made to make the model tractable in this study:

(1) The liquid metal flow is laminar, Newtonian and incompressible. The buoyance term is treated by Boussinesq approximation.

(2) The relative magnetic permeability of solid 304 stainless steel is one [13].

(3) The metal vapor in the keyhole is weakly ionized, so the gaseous phase in the model is considered as non-conductive [18].

(4) The thermoelectric effect and the Joule heat are not taken into consideration. The Lorentz force acting on the liquid filler material is neglected [19].

Table 2 Nomenclature in the simulation model.

\begin{tabular}{llll}
\hline Symbol & Nomenclature & Symbol & Nomenclature \\
\hline$a_{\mathrm{s}}$ & Sulfur activity & $\vec{S}_{\mathrm{m}}$ & Momentum source term \\
A, B & Evaporation coefficients & $\vec{s}$ & Tangential vector \\
\hline
\end{tabular}




\begin{tabular}{|c|c|c|c|}
\hline$A_{\mathrm{T}}$ & Surface tension gradient & $t$ & Time \\
\hline$\vec{B}_{0}$ & $\begin{array}{l}\text { Externally imposed magnetic field in } \\
\text { Fig. 1(b) } \\
\text { Secondarily induced magnetic field }\end{array}$ & $T$ & Temperature \\
\hline$\vec{b}$ & $\begin{array}{l}\text { from temporal variation of } \vec{B}_{0} \text { and } \\
\text { liquid flow }\end{array}$ & $T_{\mathrm{S}}, T_{\mathrm{L}}$ & Solidus and liquidus temperature \\
\hline$C_{\mathrm{Ni}}$ & Weight percentage of $\mathrm{Ni}$ & $T_{0}$ & Ambient temperature \\
\hline$c_{\mathrm{p}}$ & Specific heat & $T_{\mathrm{w}}$ & $\begin{array}{l}\text { Temperature of liquid filler } \\
\text { material }\end{array}$ \\
\hline$c_{\mathrm{pw}}$ & Specific heat of filler material & $v_{\text {evp }}$ & $\begin{array}{l}\text { Evaporation recession speed of } \\
\text { the free surface }\end{array}$ \\
\hline$d$ & $\begin{array}{l}\text { Distance between solidification front } \\
\text { and magnet center }\end{array}$ & $\vec{v}$ & Velocity vector \\
\hline$C_{\mathrm{w}}$ & Ni source from filler wire & $v_{\text {feed }}$ & Wire feeding speed \\
\hline$D_{\mathrm{Ni}}$ & Diffusion coefficient of $\mathrm{Ni}$ in iron & $v_{\mathrm{n}}$ & Normal velocity \\
\hline$D_{\mathrm{p}}$ & Penetration depth & $v_{\max }$ & Maximum velocity in weld pool \\
\hline$\vec{F}_{L}$ & Vector of Lorentz force & $v_{\mathrm{t}}$ & Tangential velocity \\
\hline$F$ & Focal length & $v_{\text {speed }}$ & Welding speed \\
\hline$\vec{g}$ & Vector of gravity acceleration & $\vec{v}_{w}$ & $\begin{array}{l}\text { Velocity vector of the liquid } \\
\text { filler material }\end{array}$ \\
\hline$H$ & Time-dependent keyhole depth & $x, y, z$ & Coordinates \\
\hline$h_{\mathrm{c}}$ & Convection heat transfer coefficient & $\alpha$ & $\begin{array}{l}\text { Angle between welding direction } \\
\text { and maximum heat flow } \\
\text { direction }\end{array}$ \\
\hline$h$ & Enthalpy & $\beta$ & Expansion coefficient \\
\hline$h_{\mathrm{w}}$ & $\begin{array}{l}\text { Energy source from the liquid filler } \\
\text { material }\end{array}$ & $\Gamma_{\mathrm{s}}$ & Surface excess at saturation \\
\hline$\vec{j}$ & Current density & $\Delta L_{\mathrm{v}}$ & Evaporation latent heat \\
\hline$k$ & Thermal conductivity & $\Delta H_{\mathrm{w}}$ & $\begin{array}{l}\text { Melting latent heat of filler } \\
\text { material }\end{array}$ \\
\hline$K$ & Carman-Kozeny equation coefficient & $\Delta H_{0}$ & Heat of absorption. \\
\hline$k_{\mathrm{b}}$ & Boltzmann constant & $\delta$ & A small number for convergence \\
\hline$k_{1}$ & Entropy factor & $\gamma_{0}$ & $\begin{array}{l}\text { Surface tension at the melting } \\
\text { point }\end{array}$ \\
\hline$m_{\mathrm{a}}$ & Molar mass & $\gamma$ & Surface tension \\
\hline$m_{\mathrm{w}}$ & Mass source from filler wire & $\varepsilon_{\mathrm{r}}$ & Emissivity \\
\hline$\vec{n}$ & Normal vector & $\begin{array}{l}\eta_{\mathrm{w}}, \eta_{\text {wloss }} \\
\eta_{\mathrm{k}}, \eta_{\text {kloss }}\end{array}$ & Allocation of laser energy \\
\hline$N_{\mathrm{a}}$ & Avogadro constant & $\kappa$ & Curvature \\
\hline$p$ & Hydrodynamic pressure & $\mu$ & Dynamic viscosity \\
\hline$p_{c a}$ & Capillary pressure & $\mu_{0}$ & Permeability of vacuum \\
\hline$p_{r}$ & Recoil pressure & $\mu_{\mathrm{m}}$ & Permeability \\
\hline$p_{\text {vapor }}$ & Stagnation pressure of metal vapor & $\rho$ & Density \\
\hline$P_{\mathrm{L}}$ & Laser power & $\rho_{\mathrm{w}}$ & Density of filler wire \\
\hline
\end{tabular}




\begin{tabular}{|c|c|c|c|}
\hline$q_{\mathrm{L}}$ & Laser energy density & $\sigma$ & Stefan-Boltzmann constant \\
\hline$q$ plume & $\begin{array}{l}\text { Heat flux from the high-temperature } \\
\text { plume }\end{array}$ & $\sigma_{\mathrm{e}}$ & Electrical conductivity \\
\hline$q_{\text {recond }}$ & $\begin{array}{l}\text { Heat flux from the metal vapor's re- } \\
\text { condensation }\end{array}$ & $\phi$ & Volume fraction \\
\hline$r_{\mathrm{w}}$ & Radius of filler wire & $\phi_{\mathrm{w}}$ & $\begin{array}{l}\text { Volume source from the filler } \\
\text { material }\end{array}$ \\
\hline$R_{0}$ & Distribution radius of heat source & $\phi_{\text {steel }}$ & Volume fraction of the steel \\
\hline$R_{\mathrm{g}}$ & Gas constant & $\tau_{\mathrm{ma}}$ & Marangoni stress \\
\hline$S_{q}$ & Heat source term & $\tau_{\text {vapor }}$ & Shear stress of metal vaopr \\
\hline
\end{tabular}

3.1 Governing equations

Under the above assumptions, the governing equations in a fixed Cartesian coordinate are written as below:

- Mass equation

$$
\nabla \cdot \vec{v}=\frac{m_{\mathrm{w}}}{\rho}
$$

- Momentum equation

$\rho\left(\frac{\partial \vec{v}}{\partial t}+\vec{v} \cdot \nabla \vec{v}\right)=-\nabla p+\mu \nabla^{2} \vec{v}+\beta \rho\left(T-T_{0}\right) \vec{g}-\rho \vec{g}-\mu K \vec{v}+m_{\mathbf{w}} \vec{v}_{\mathbf{w}}+\vec{S}_{\mathbf{m}}$

The third to sixth term in right hand side of Eq. (2) represent the buoyance, gravity, frictional dissipation in the mushy zone and momentum impact from the liquid filler material, respectively.

- Energy equation

$$
\rho\left[\frac{\partial h}{\partial t}+(\vec{v} \cdot \nabla) h\right]=\nabla \cdot(k \nabla T)+h_{\mathrm{w}}+S_{q}
$$

- Volume-of-fluid (VOF) equation

$$
\frac{\partial \phi}{\partial t}+\nabla \cdot(\vec{v} \phi)=\phi_{w}
$$

- Element transport equation

$$
\frac{\partial \phi_{\text {steel }} \rho_{\text {steel }} C_{\mathrm{Ni}}}{\partial t}+\nabla \cdot\left(\phi_{\text {steel }} \rho_{\text {steel }} \vec{v} C_{\mathrm{Ni}}-\phi_{\text {steel }} D_{\mathrm{Ni}} \nabla C_{\mathrm{Ni}}\right)=C_{\mathrm{w}}
$$

- Magnetic induction equation

The magnetic induction method is used to calculate the electromagnetic field. From the Ohm's law and the Maxwell's equations, the induction equations can be derived as:

$$
\frac{\partial \vec{b}}{\partial t}+(\vec{v} \cdot \nabla) \vec{b}=\frac{1}{\mu_{m} \sigma_{\mathrm{e}}} \nabla^{2} \vec{b}+\left(\left(\vec{B}_{0}+\vec{b}\right) \cdot \nabla\right) \vec{v}-(\vec{v} \cdot \nabla) \vec{B}_{0}
$$


The secondary induced magnetic field $\vec{b}$ which is the variable to be calculated in Eq. (6)

comes from temporal variation of $\vec{B}_{0}$ and liquid flow. Considering that the geometry of electromagnet is not physically included in the model, the experimentally-measured $\vec{B}_{0}$ from Fig. $1(\mathrm{~b})$ is imposed into the model directly during the calculation.

After $\vec{b}$ is solved, the current density and the Lorentz force can be calculated as:

$\vec{j}=\frac{1}{\mu_{m}} \nabla \times\left(\vec{B}_{0}+\vec{b}\right)$

$\vec{F}_{L}=\vec{j} \times\left(\vec{B}_{0}+\vec{b}\right)$

\subsection{Boundary conditions}

The laser energy, heat loss and the secondary heat flux from the high-temperature plume and the metal vapor's re-condensation are implemented on the keyhole wall:

$k \frac{\partial T}{\partial \vec{n}}=q_{L}-h_{c}\left(T-T_{0}\right)-\sigma \varepsilon_{\mathrm{r}}\left(T^{4}-T_{0}^{4}\right)-\rho v_{\mathrm{evp}} \Delta L_{v}+q_{\mathrm{plume}}+q_{\mathrm{recond}}$

The second to fourth term at the right hand side represent the heat loss from convection, radiation and evaporation, respectively. The evaporation recession speed $v_{\text {evp }}$ can be calculated from the velocity jump across the Knudsen layer [20].

The recoil pressure, the stagnation pressure of high-velocity metal vapor and the capillary pressure are applied on the normal direction of keyhole wall. The Marangoni force and the shear stress of metal vapor are applied on the tangential direction of keyhole wall.

$-p+2 \mu \frac{\partial v_{\mathrm{n}}}{\partial \vec{n}}=-p_{r}-p_{\text {vapor }}+p_{c a}$

$-\mu \frac{\partial v_{\mathrm{t}}}{\partial \vec{n}}=\tau_{m a}+\tau_{\text {vapor }}$

Compared with the realistic workpiece, the simulation domain is small in $\mathrm{X}$ and $\mathrm{Y}$ directions. Hence, continuum boundary is used on the side surface of the steel workpiece, which makes the simulation domain semi-infinitely large for thermal conduction [21]. The side surfaces of steel workpiece are set as electrically conducting, and the other surfaces are set as insulating. The melting of the filler wire is not simulated in the model. A moving mass inlet of liquid filler material is set at the top of the model. The temperature is taken from literature [22] and the velocity is measured from high-speed images. A summary of the boundary conditions is shown in Fig.2. 


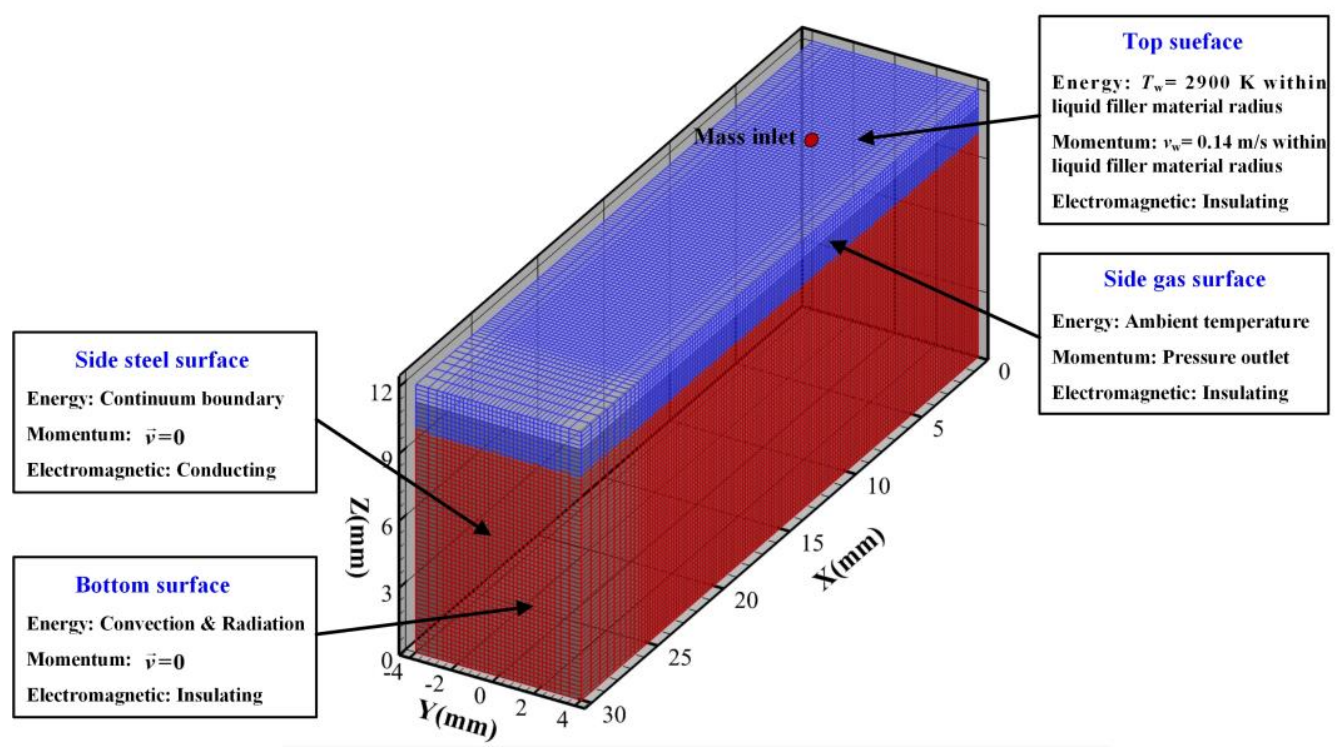

Fig. 2 Boundary conditions of simulation model

\subsection{Welding models}

Compared with autogenous LBW, the energy allocation in the WFLBW is more complex. Four coefficients should be given to describe the energy allocation: the absorption coefficient at the filler wire $\eta_{\mathrm{w}}$, the loss coefficient from the filler wire $\eta_{\text {wloss, }}$, the absorption coefficient on the keyhole wall $\eta_{\mathrm{k}}$ and the loss coefficient from the keyhole wall $\eta_{\mathrm{kloss}}$.

According to the study of Arata et al., the average temperature of the liquid filler material is assumed to be $2900 \mathrm{~K}$ under current welding parameter [22]. The absorption coefficient at the filler wire are calculated as follows:

$\eta_{\mathrm{w}}=\frac{\pi v_{\text {feed }} \rho_{\mathrm{w}} r_{\mathrm{w}}^{2}\left[c_{\mathrm{pw}}\left(T_{\mathrm{w}}-T_{0}\right)+\Delta H_{\mathrm{w}}\right]}{P_{\mathrm{L}}} \approx 7.2 \%$

The energy loss due to laser reflection on the filler wire is a function of laser power, wire feeding speed and focal length, which can be fitted into the following equation [23]:

$\eta_{\text {wloss }}=2.07 P_{\mathrm{L}}^{-2.11} F^{0.82} v_{\text {feed }}^{0.76} \approx 5.5 \%$ (13)

More than $85 \%$ of the laser entering the keyhole will be absorbed because of the multireflections between the keyhole wall, so the absorption coefficient on the keyhole wall is determined as [24]:

$\eta_{k}=0.85 \times\left(1-\eta_{\mathrm{w}}-\eta_{\text {wloss }}\right) \approx 70 \%$

A rotary Gauss volumetric heat source is used in the model to represent the spatial distribution of the laser energy in the keyhole [25]. 
$q=\frac{9 \eta_{k} P_{L}}{\pi R_{0}^{2} H\left(1-\mathrm{e}^{-3}\right)} \exp \left[\frac{-9\left(\left(x-v_{\text {speed }} t\right)^{2}+y^{2}\right)}{R_{0}^{2} \ln \left(\frac{H}{z}\right)}\right]$

The temperature of vapor plume in the fiber laser welding of steel can reach up to $6000 \mathrm{~K}$ [26], and it provides an additional heating effect on the keyhole, influencing the fusion line shape, especially on the upper part. Although severe evaporation occurs in the keyhole, $90 \%$ of the metal vapor is condensed back to the weld pool [27]. The release of the evaporation latent heat also acts as an additional heat source. In this study, the spatial distribution of $q_{\text {plume }}$ and $q_{\text {recond }}$ are determined based on the work of Muhammad et al.[28].

The keyhole formation is mainly driven by the recoil pressure involving the evaporation of material. It can be calculated by the following equation [29]:

$p_{r}=\frac{A B}{\sqrt{T}} \exp \left(-\frac{m_{a} \Delta L_{v}}{N_{a} k_{b} T}\right)$

The dependency of surface tension coefficient on temperature can be expressed as $\gamma=\gamma_{0}-A_{T}\left(T-T_{\mathrm{L}}\right)-R_{\mathrm{g}} T \Gamma_{\mathrm{s}} \ln \left(1+K_{\mathrm{s}} a_{\mathrm{s}}\right)$

$K_{\mathrm{s}}=k_{l} \exp \left(\frac{-\Delta H_{0}}{R_{\mathrm{g}} T}\right)$

Then, the capillary pressure and the Marangoni stress are calculated as:

$p_{\text {ca }}=\gamma \kappa(18)$

$\tau_{\mathrm{ma}}=\frac{\partial \gamma}{\partial T} \frac{\partial T}{\partial \vec{s}}$

The high-velocity metal vapor also shows non-negligible impact on the transient evolution of the keyhole [30]. In this study, the stagnation pressure and the shear stress produced by the metal vapor are employed by an empirical model developed by Cho et al., in which the velocity of the metal vapor is assumed to have a linear increase from the keyhole bottom to the keyhole entrance [31].

\subsection{Numerical algorithm}

The geometric model has dimensions of $30 \mathrm{~mm}$ in length, $8 \mathrm{~mm}$ in width and $12 \mathrm{~mm}$ in thickness, as shown in Fig. 2. A gaseous phase layer $(10 \mathrm{~mm} \leq z \leq 12 \mathrm{~mm})$ is initialized above the workpiece for using the VOF method to track the free surface. The center domain $(-2.5 \mathrm{~mm} \leq y \leq 2.5$ 
$\mathrm{mm}$ ) has a fixed cell size of $0.2 \mathrm{~mm}$. The other domains are divided into coarser cells, expanding from $0.2 \mathrm{~mm}$ to $1 \mathrm{~mm}$ gradually.

All the transport equations are solved by the commercial finite volume method software ANSYS Fluent. The magnetic field, energy, momentum and Ni content scalar are discretised spatially by the second order upwind method. The PISO algorithm is applied for the velocity-pressure coupling. A high performance computing cluster in the Federal Institute for Materials Research and Testing (BAM) is used to run the calculation program, and it takes about sixty hours to simulate around $0.9 \mathrm{~s}$ real time WFLBW. The physical properties of base metal and filler wire are taken from the literature [32-36]. The steel properties in the model are percentage-weighted averages of the base metal and the filler material.

\section{Results and discussion}

4.1 MHD behavior and weld pool behavior

Two circulating electric currents are induced in the workpiece, as shown in Fig. 3, and their directions could be either clockwise or counter-clockwise depending on the oscillating magnetic field. These two circulating currents are almost separated by the keyhole because the electric conductivity of 304 steel decreases with temperature rising and the gaseous phase in the keyhole is non-conducting. The peak value of current density is around $1.2 \times 10^{7} \mathrm{~A} / \mathrm{m}^{2}$.

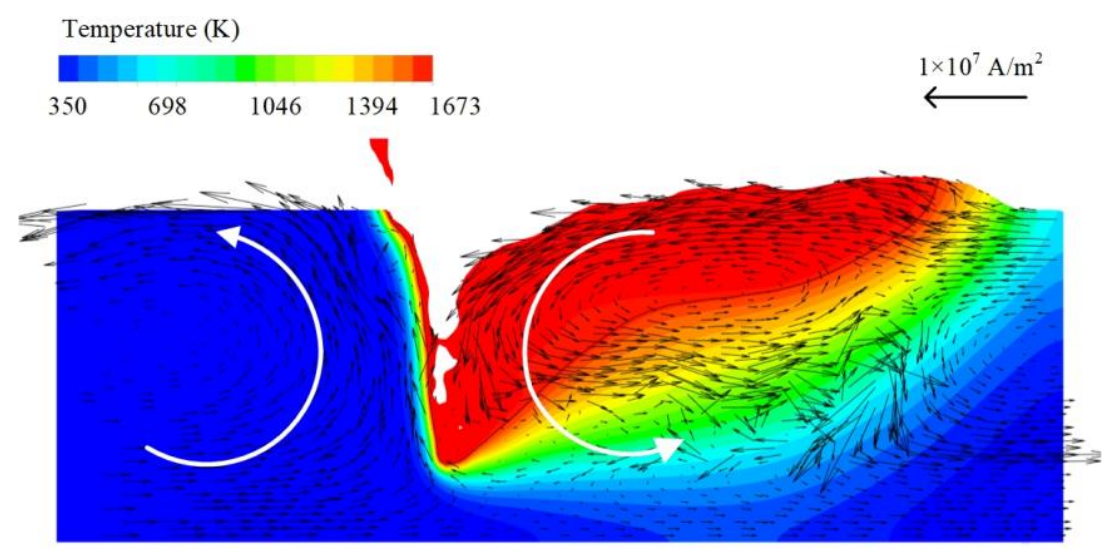

Fig. 3 Induced electric current density at longitudinal section

Fig. 4 shows the secondary magnetic field from temporal variation of external magnetic field and liquid flow. Typically, its maximum value occurs at the cold metal region before the weld pool due to the high electrical conductivity. However, only the secondary magnetic field in the weld pool is plotted in Fig. 4 for a better clarity, and the value in the solid region is set as 0 . The secondary 
magnetic field is small at the surface region and becomes larger near the solid/liquid boundary. The maximum value in the weld pool is only $19 \mathrm{mT}$ which is quite negligible compared with the external magnetic field.

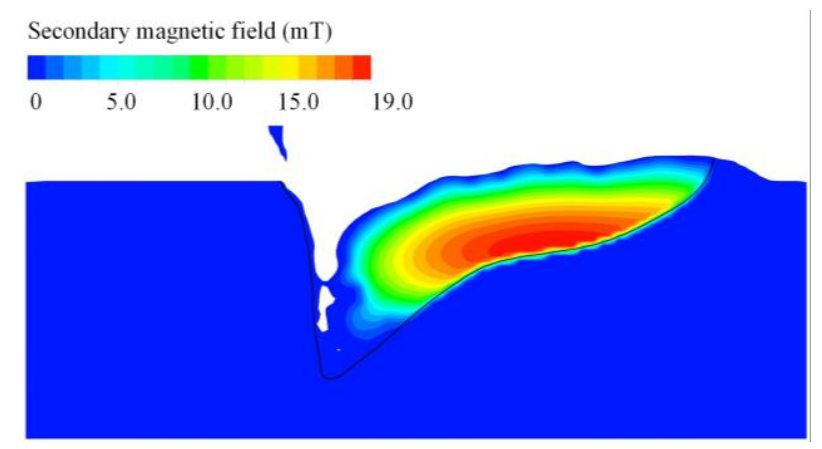

Fig. 4 Secondary magnetic field in the wed pool.

The oscillating magnetic field and its self-induced eddy current will produce an oscillating Lorentz force in the workpiece. Fig. 5 also only gives the distribution of Lorentz force in the weld pool. The Lorentz force becomes expanding or contractive alternatively in a frequency of $7200 \mathrm{~Hz}$ which is double of the magnetic field frequency. Since the magnetic flux density is larger at the upper part of the weld pool, the induced Lorentz force is also much stronger there. In the expanding period, the Lorentz force at the top region is nearly upward with a peak value around $1.6 \times 10^{6} \mathrm{~N} / \mathrm{m}^{3}$. In contrast, it is downward with a peak value around $1.9 \times 10^{6} \mathrm{~N} / \mathrm{m}^{3}$ in the contractive period. The timeaveraged Lorentz force at the top region is downward and in the order of magnitude of $10^{5} \mathrm{~N} / \mathrm{m}^{3}$. The calculated value is coincident with other simulation study from Bachman et al. [13]. An electromagnetic stirring will be generated in the weld pool to enhance the material mixing.

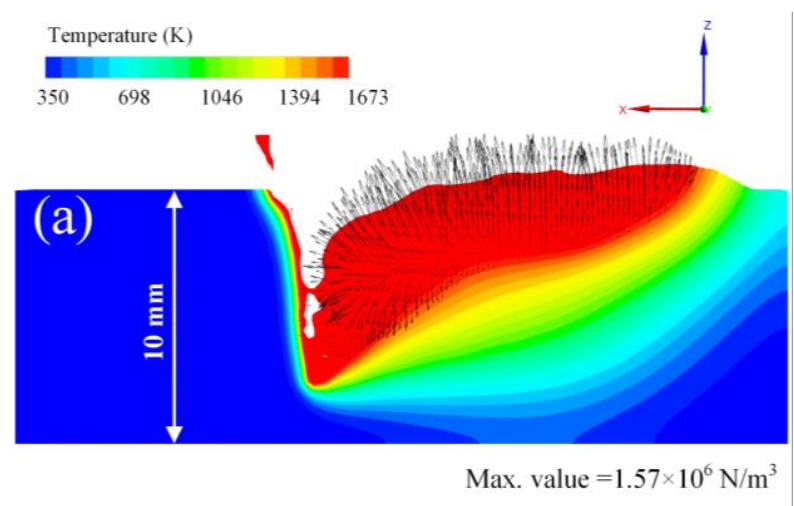




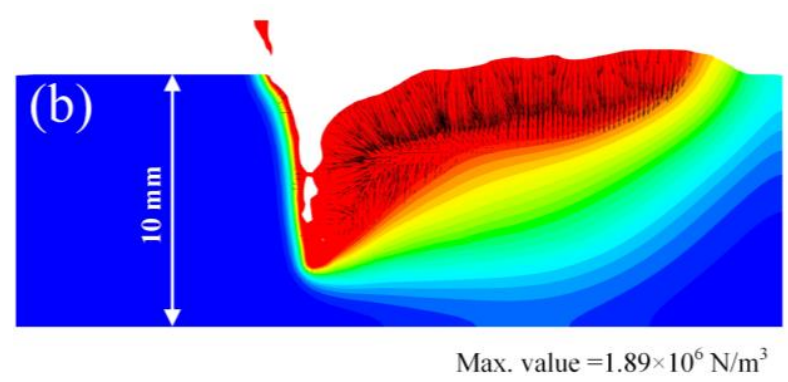

Fig. 5 Distribution of the Lorentz force in the weld pool: (a) $t_{0}$ (b) $t_{0}+1 / 4 \times$ magnetic field period

The calculated temperature profile and velocity field are given in Fig. 6. The free surface of weld pool is considerably depressed under the recoil pressure, and a deep and narrow keyhole with an extremely thin liquid metal layer on its front wall forms in the WFLBW, as shown in Fig. 6(a). The metal flow on the keyhole front wall is quite irregular. The metal melted at the keyhole front wall and the liquid metal from the filler wire flow backward round the keyhole, and continue to flow backward along the periphery of the weld pool. Then the liquid metal changes the direction at the middle part of the weld pool, and flows forward along the longitudinal section. The dominant flowing routine of liquid metal is marked with white arrows. The upper part of the weld pool is considerably elongated up to $20 \mathrm{~mm}$, and the lower part is relatively shorter. Fig. 7 gives the high-speed image of weld pool. There is a good agreement between the calculated weld pool length and the experimental one. The electromagnetic stirring does not show a remarkable influence on the fundamental routine of material flow in EMS-WFLBW, comparing Fig. 5(a) and (b). However, the Lorentz force pushes the liquid metal to flow downward. When the liquid metal flows along the longitudinal section, its direction changes from forward to downward.

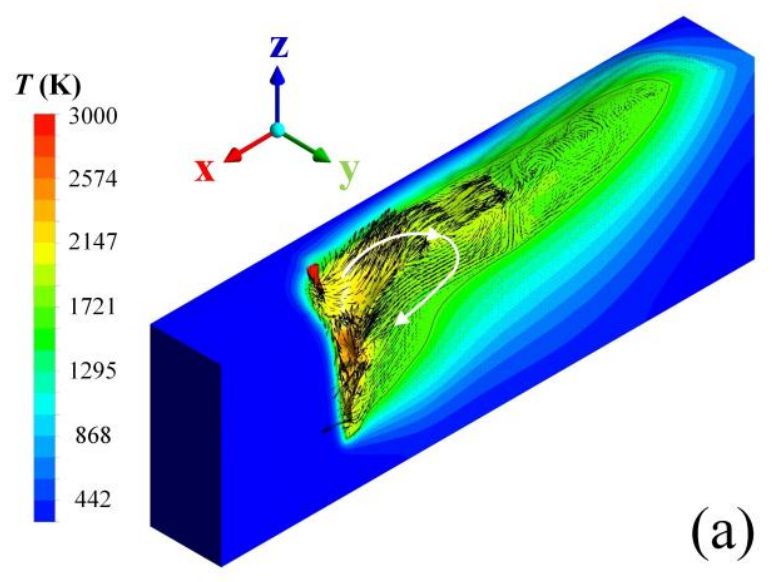




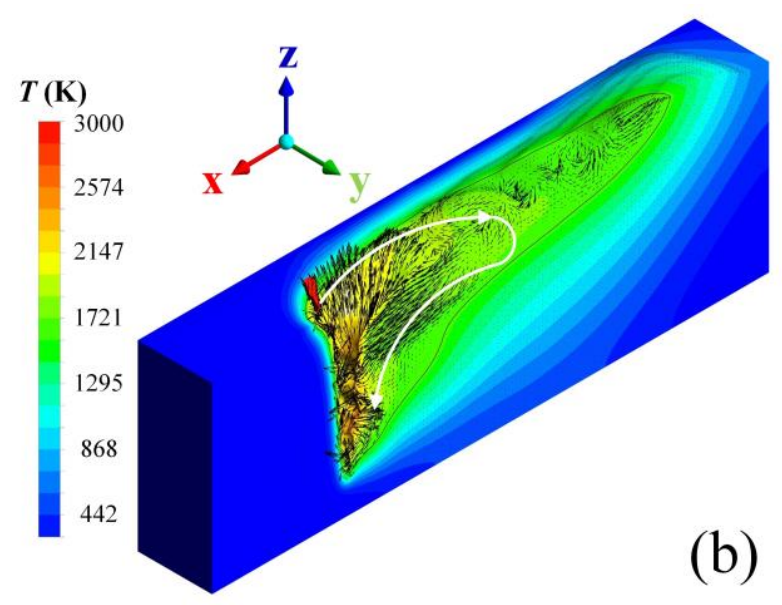

Fig. 6 Calculated temperature profile and velocity field: (a) WFLBW, (b) EMS-WFLBW

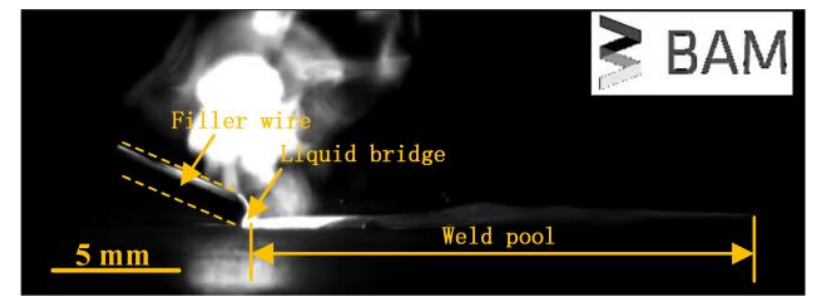

Fig. 7 Image of weld pool captured by high-speed camera

Fig. 8 presents the comparison of velocity magnitude between WFLBW and EMS-WFLBW. The averaged velocity inside the weld pool of WFLBW is around $0.2 \mathrm{~m} / \mathrm{s} \sim 0.4 \mathrm{~m} / \mathrm{s}$, which agrees with the experimental data [37]. For both processes, the peak velocity is located at the keyhole wall because the recoil pressure is the predominant driving force. In region A, there is no apparent influence on the velocity magnitude from the Lorentz force. In the rear part (region B) and lower part (region C) of the weld pool, the velocity magnitude is increased under the stirring. According to the MHD theory, there are two components in the Lorentz force, one from the temporal variation of magnetic field and one from the liquid flow. The Lorentz force from liquid flow is always opposite to the flowing direction to decelerate the melt flow, namely magnetic braking. However, the effect magnetic braking is masked by the stirring effect from the temporal variation of magnetic field in this study. 


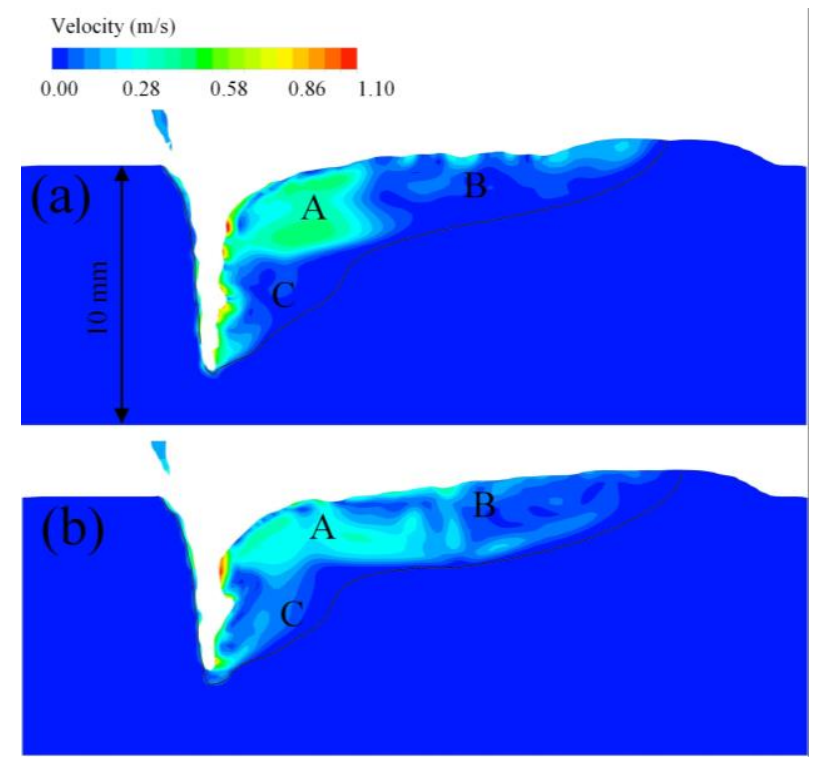

Fig. 8 Velocity magnitude at the longitudinal section: (a) WFLBW, (b) EMS-WFLBW

Fig. 9 shows the comparison between the numerically calculated fusion line shape and the experimental one. An accurate prediction of fusion zone profile is achieved for both processes, which proves the reasonability of the numerical model. The predicted contour line of reinforcement for WFLBW also shows a good agreement with the experimental result, but a larger error exists in the simulation of EMS-WFLBW. It is because that the weld bead surface of EMS-WFLBW has more fluctuation which cannot be reproduced by the model so far.
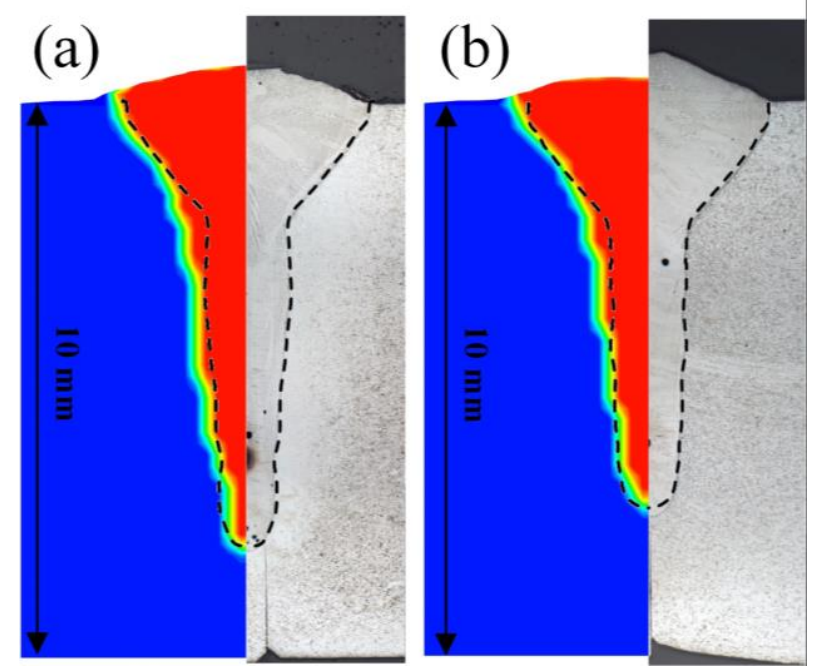

Fig. 9 Experimental and numerical fusion line shape: (a) WFLBW, (b) EMS-WFLBW

The Ni distribution can be used to characterize the mixing in the weld pool. The simulated distribution of Ni content in the final weld is plotted in Fig. 10. It can be seen intuitively in Fig. 10(a) 
that the added $\mathrm{Ni}$ from the filler wire concentrates on the upper part in WFLBW. After the electromagnetic stirring is introduced, the Ni can be transferred to the lower part of the weld, as shown in Fig. 10(b). The Ni content along the center line of transverse section is shown in Fig. 11 and the experimental data are measured by the EDX line scanning and averaged over a distance of $500 \mu \mathrm{m}$. The depth of uniform region is only $3.5 \mathrm{~mm}$ in WFLBW. A transition region can be observed below the uniform region, in which the Ni content decreases from $16 \%$ to the level of base metal. The depth of uniform region increases to $5.5 \mathrm{~mm}$ under the stirring of Lorentz force. Correspondingly, the transition region is also narrowed. The comparison between calculated and numerical results also shows a good agreement.

The element transport is directly determined by the thermal process and fluid flow in weld pool. It can be divided into two factors: diffusion and advection. The ratio of advection to diffusion can be evaluated by the Peclet number $(\mathrm{Pe})$, which gives $P e=D_{\mathrm{p}} v_{\max } / D_{\mathrm{Ni}} \approx 1 \times 10^{6}$. It indicates that the diffusion is quite negligible and the Ni distribution is determined by the advection (fluid flow). Although the filler material with high Ni content impacts the upper region of keyhole front wall first, the keyhole front wall is not the main transfer routine considering the irregular flow direction. The filler material is transferred along the dominant flowing routine, as shown in Fig. 6. In WFLBW, the forward flow along the longitudinal section is nearly parallel to the welding direction and the velocity component in $z$ direction is small, which is not beneficial for the downward transfer of the additional material. In the EMS-WFLBW, the downward flow which is enhanced by the electromagnetic stirring can bring the Ni to the root of weld pool.

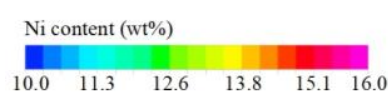

(a)

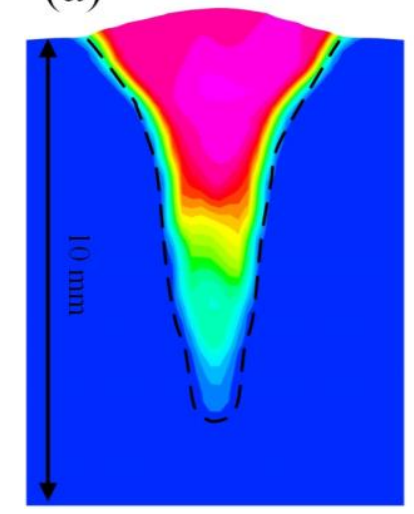

Ni content (wt\%)

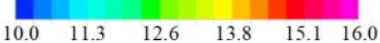

(b)

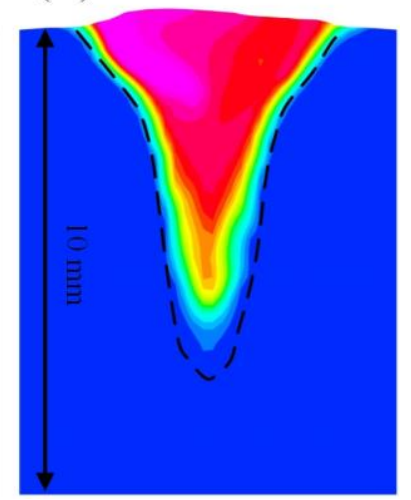

Fig. 10 Calculated Ni distribution on transverse section: (a) WFLBW, (b) EMS-WFLBW 

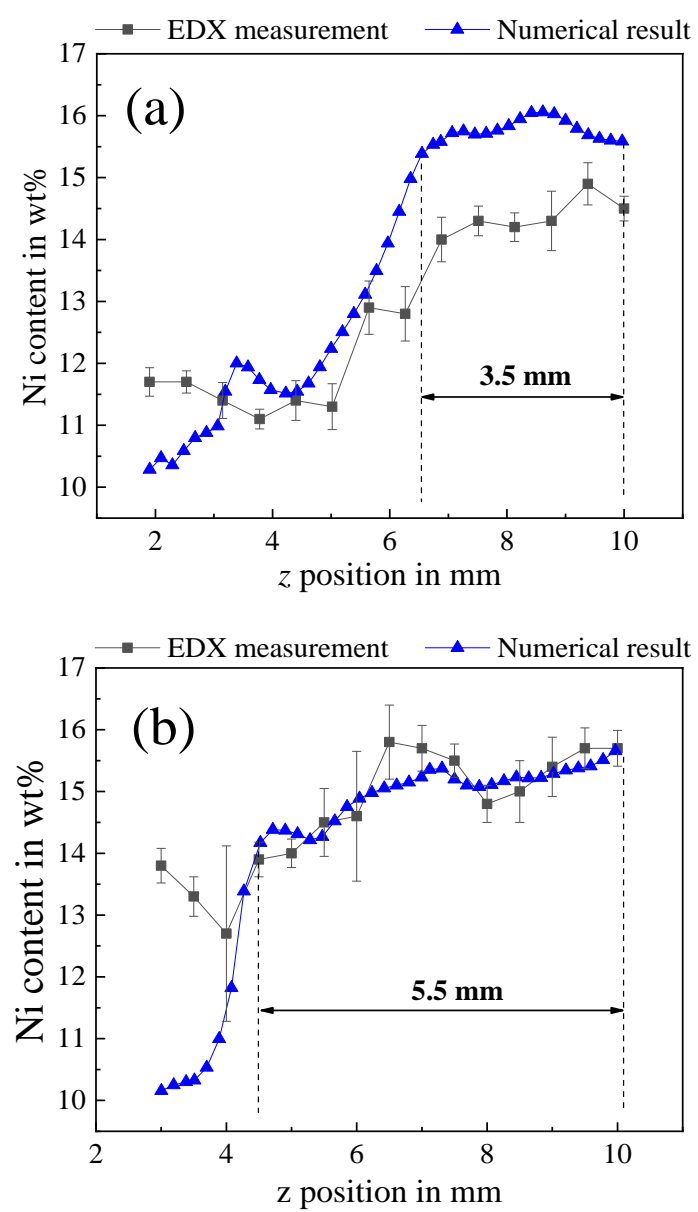

Fig. 11 Comparison of calculated and experimental Ni content along center line of transverse section: (a) WFLBW, (b) EMS-WFLBW

\subsection{Solidification microstructure}

The above-mentioned results indicate that the electromagnetic stirring enhances the thermal fluid flow significantly. It is reasonable to infer that it influences the solidification parameter as well, and consequently, changes the final microstructure. Usually, the grain shape and size are determined by several key solidification parameters including the temperature gradient ahead of the solidification front $(|\vec{G}|)$, solidification rate $(R)$, cooling rate $|\vec{G}| R$ and morphology factor $|\vec{G}| / R$. They are calculated by the following equations [38].

$$
\begin{aligned}
& |\vec{G}|=\sqrt{\left(\frac{\partial T}{\partial x}\right)^{2}+\left(\frac{\partial T}{\partial y}\right)^{2}+\left(\frac{\partial T}{\partial z}\right)^{2}} \\
& R=v_{\text {speed }} \cos \alpha
\end{aligned}
$$

Fig. 12 shows the vector field of $\vec{G}$ at $\mathrm{z}=9 \mathrm{~mm}$ and $\mathrm{z}=6 \mathrm{~mm}$, along with the weld pool geometry. The red region represents the solidified weld zone, and the vector at each point is calculated 
at the moment when the solidification front passes through, i.e. solidification starts. The weld pool in WFLBW has a narrow and tear-dropped shape. Therefore, the direction of $\vec{G}$ (i. e. the maximum local heat flow direction) along which the columnar grain grows is mainly along the transverse plane at the position of $\mathrm{z}=9 \mathrm{~mm}$. It means that the grain growth direction will have a very small inclination angle to the transverse plane. The direction of $\vec{G}$ is almost vertical to the longitudinal plane in the position of $\mathrm{z}=6 \mathrm{~mm}$, and thereby the grain may grow along the $y$ direction. By comparing the Fig. 12 (a) and (b), it is suggested that the electromagnetic stirring does not bring noticeable variation on the direction of $G$, and correspondingly, on the orientation of grain.
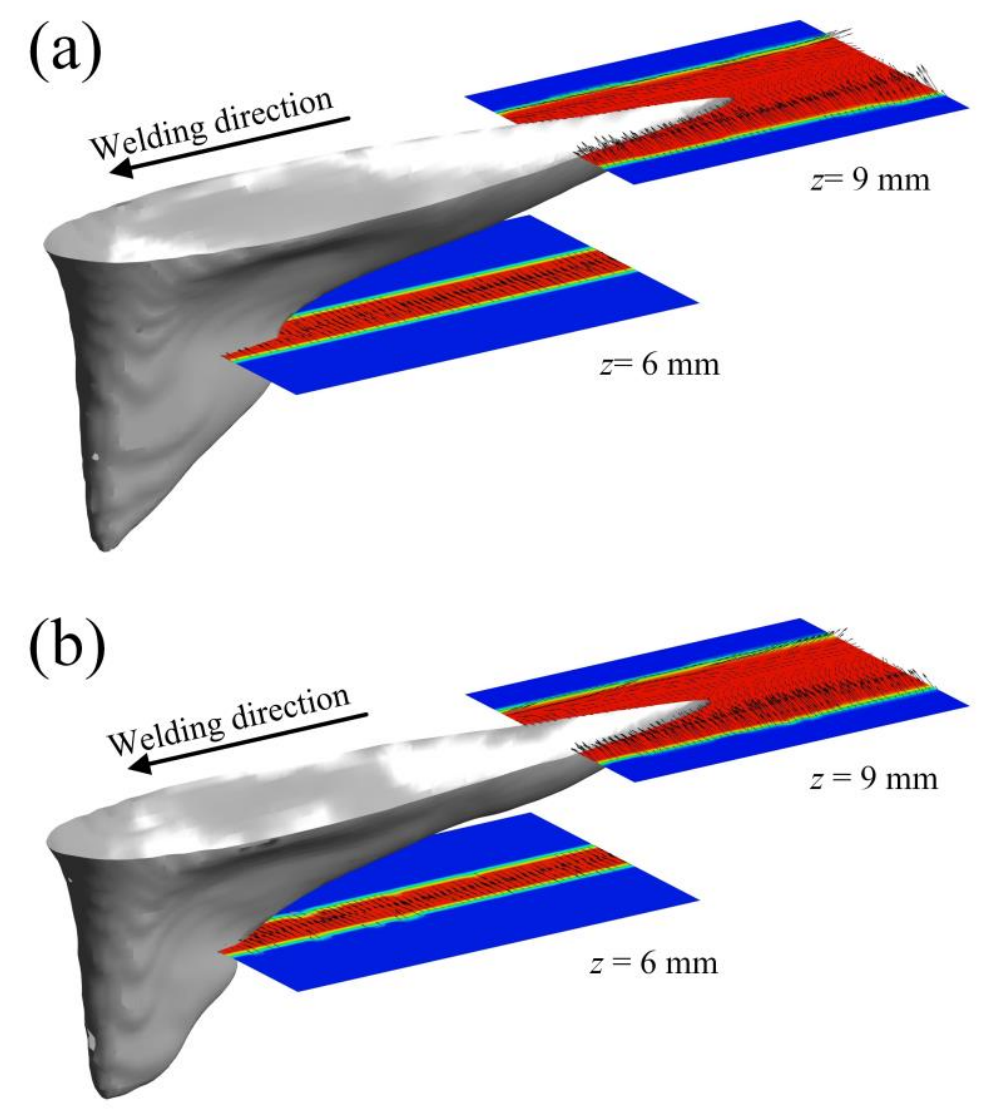

Fig. 12 Calculated 3D vector of temperature gradient ahead of the solidification front at $\mathrm{z}=9 \mathrm{~mm}$ and $\mathrm{z}=6 \mathrm{~mm}$ : (a) WFLBW, (b) EMS-WFLBW.

Fig. 13 shows the grain morphology at the horizontal plane which is $1 \mathrm{~mm}$ from the top surface. For both processes, the grains only have a small inclination angle with respect to the transverse plane, which is well coincident with the numerical results. It could be a confusion that the upper fusion zone is composed of columnar grains and equiaxial grains. Actually, the "equiaxial grains" are small cross 
sectional areas of the columnar grains. It means that the realistic grain size cannot be reflected from the horizontal metallograph.
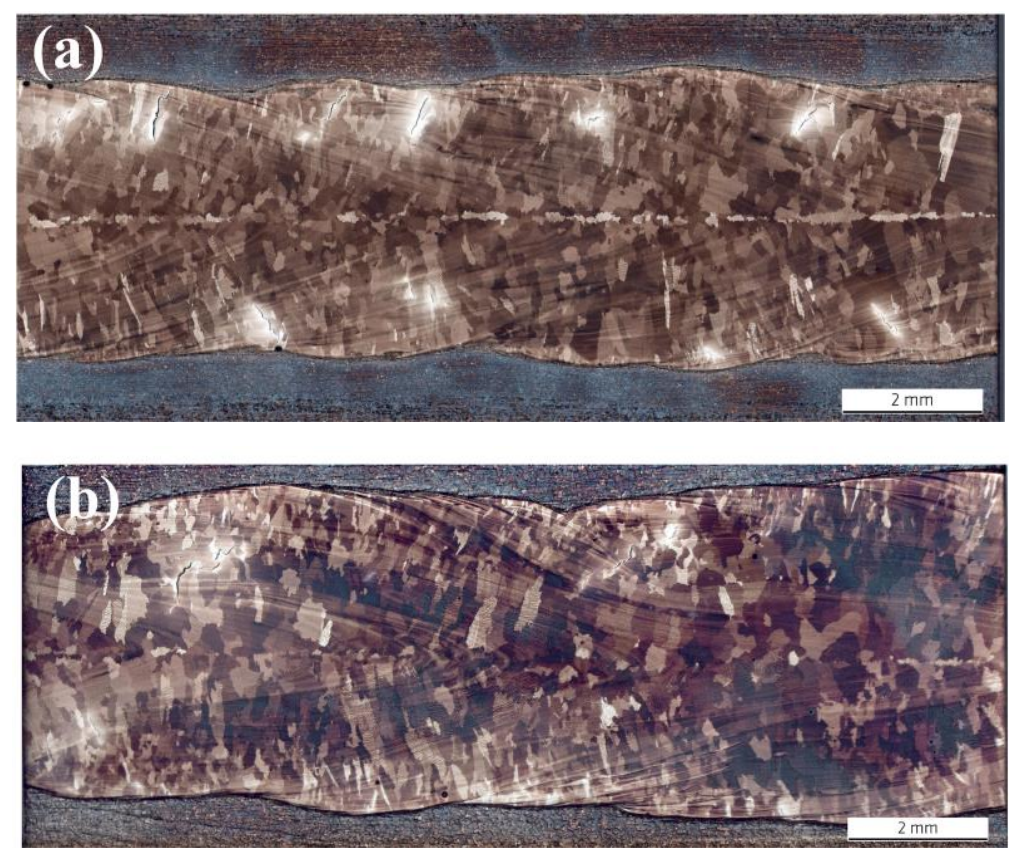

Fig. 13 Microstructure morphology at horizontal plane $\mathrm{z}=9 \mathrm{~mm}$ : (a) WFLBW, (b) EMS-WFLBW

The EBSD maps at different positions of transverse section are shown in Fig. 14. The fusion zone is dominated by columnar grains which grows epitaxially from the fusion line to the center line of weld, and few equiaxed grains are observed for both welding processes. By comparing Fig. 14 (a) (f), it can be confirmed that the grains at the upper part of the weld are significantly refined in the EMS-WFLBW. The averaged grain size reduces from $72 \mu \mathrm{m}$ to $60 \mu \mathrm{m}$ in region $\mathrm{I}$, and from $123 \mu \mathrm{m}$ to $91 \mu \mathrm{m}$ in region II. However, it is worth noting that no refinement occurs in region III in the EMSLBW, instead, the grains become even coarser, from $91 \mu \mathrm{m}$ to $124 \mu \mathrm{m}$. 


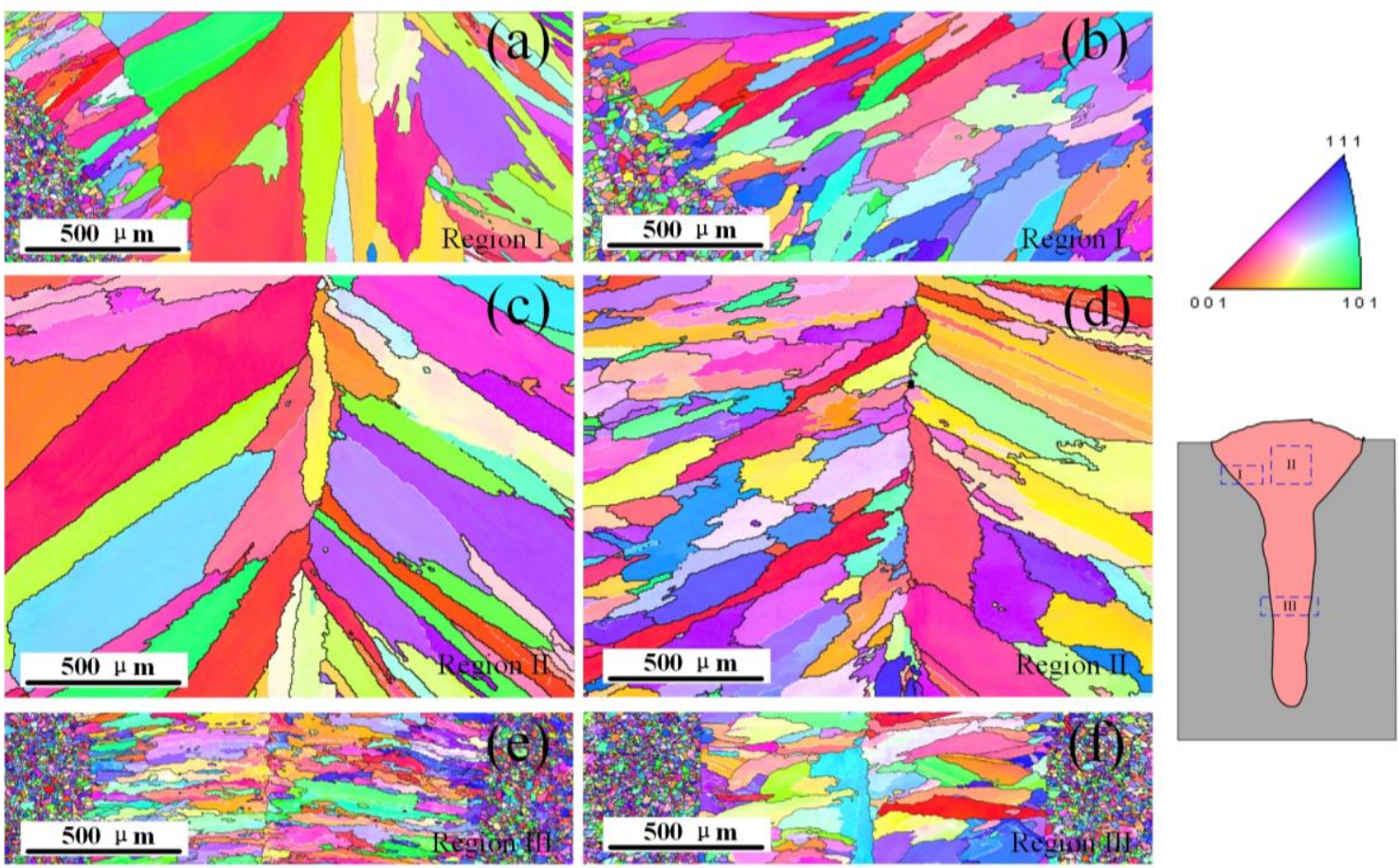

Fig. 14 EBSD maps at different positions of transverse section: (a), (c) and (e) from WFBLW, (b), (d) and (f) from EMS-WFLBW

The grain refinement was also reported in the laser + arc hybrid welding of austenitic stainless steel with steady magnetic field and it was supposed that the dendrite fragmentation was responsible for the refinement [9]. However, the grain refinement by an oscillating magnetic field in the LBW results from more complex phenomena. The $|\vec{G}|$ and $R$ will be influenced by the enhanced convection. The columnar growth may also be supressed directly by the mechanical fragmentation from electromagnetic stirring [39]. These influences are integrated, and can not be decoupled without the accurate data of the thermal fluid dynamics.

In this paper, the calculated weld pool data are used to explain the refining or coarsening of grain. Fig. 15 shows the temperature gradient and the solidification rate in the transverse section, in which the reinforcement part is excluded. The effect of electromagnetic stirring on the dendrite fragmentation can be evaluated by a factor based on Flemings' criterion for local remelting when the fluid flow velocity along the temperature gradient is larger than the solidification rate [40], which gives

$F_{\mathrm{cr}} \approx \frac{1}{R} \frac{K}{f_{\mathrm{L}} \mu} \frac{B_{\mathrm{rms}}^{2}}{\mu_{0} d}$

If $F_{\mathrm{cr}}>1$, the dendrite arm will be fragmentated by the electromagnetic stirring to suppress the growth of columnar grain. The contour of $F_{\mathrm{cr}}$ on the transverse section is shown in Fig. 16, and the black line 
represents the isoline of $F_{\mathrm{cr}}=1$. Similar to Fig. 12, each point in Fig. 15 and Fig. 16 is calculated when the solidification front passes through.

The different positions on the transverse section solidify at different times. The region near the fusion line usually solidifies before the region near the central line. $R$ is low near the fusion line because the maximum heat flow direction is almost perpendicular to the welding direction in this region. The region near the central line solidifies later with a small $\alpha$ angle, and thus has a high solidification rate. $|\vec{G}|$ is found to be high at the bottom of weld as well as the region near the fusion line. The peak value is about $1 \times 10^{6} \mathrm{~K} / \mathrm{m}$, which is close to the calculated value in Ref.[2]. It decreases gradually as the solidification front advances towards the top region near the central line.

The WFLBW and the EMS-WFLBW have similar $|\vec{G}|$ and $R$ at the upper part of the weld, as shown in Fig. 15. It means that the grain refinement in region I and II is not dominated by the thermal factors. The Lorentz force is strong enough to fragmentate the dendrite arm near the fusion line at the upper part of weld (region I), as shown in Fig. 16. When the solidification front passes through the top region near the central line (region II), the electromagnet has moved to a far position. The magnetic flux density is below $80 \mathrm{mT}$, and the $F_{\text {cr }}$ value decreases below 0.5 . The dendrite arm can not be fragmentated by a weak Lorentz force. However, some broken dendrites in the region I can be carried into the region II by the transverse convection (Fig. 6), and may act as substrates for the nucleation of new grains [41]. Therefore, the columnar growth at upper part is suppressed and the grain size is refined.

As the fragmentation effect of electromagnetic stirring is proportional to the square of magnetic flux density which decreases rapidly along the thickness direction, no fragmentation occurs at region III $\left(F_{\mathrm{cr}}<0.65\right)$. The EMS-WFLBW has a similar $|\vec{G}|$ with WFLBW, but its $R$ is much lower than what in WFLBW $(0.005 \mathrm{~m} / \mathrm{s}$ vs. $0.014 \mathrm{~m} / \mathrm{s})$. The region III in EMS-WFLBW experiences a lower cooling rate $(|\vec{G}| R)$, which produces coarser columnar grain. 


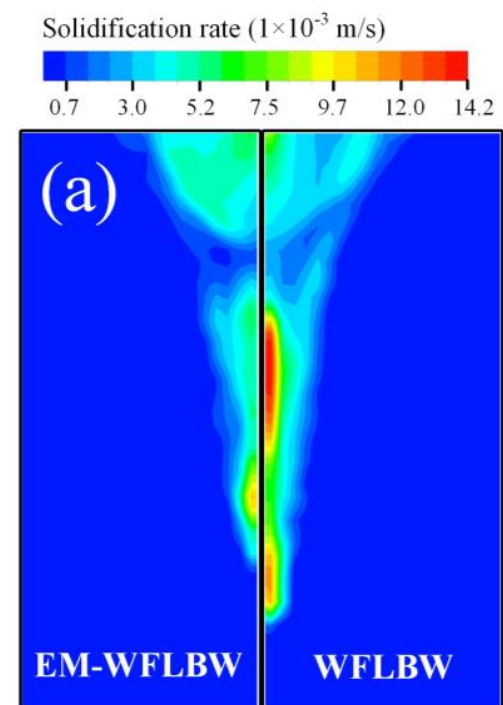

$2 \mathrm{~mm}$
Temperature gradient $\left(1 \times 10^{5} \mathrm{~K} / \mathrm{m}\right)$
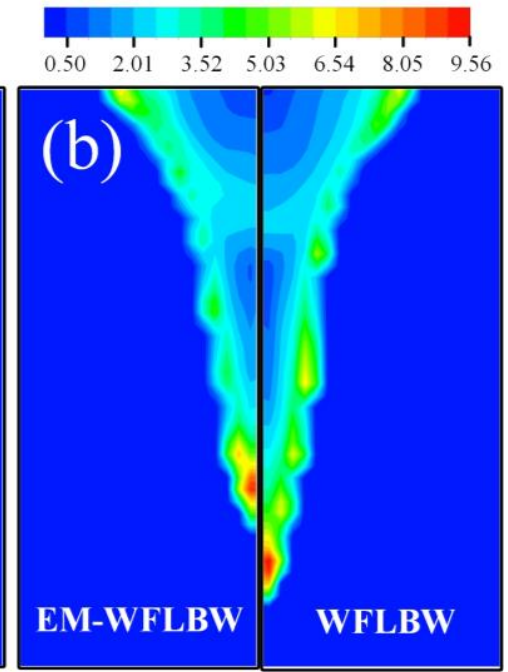

$2 \mathrm{~mm}$

Fig. 15 Solidification parameters on transverse section: (a) solidification rate, (b) temperature gradient

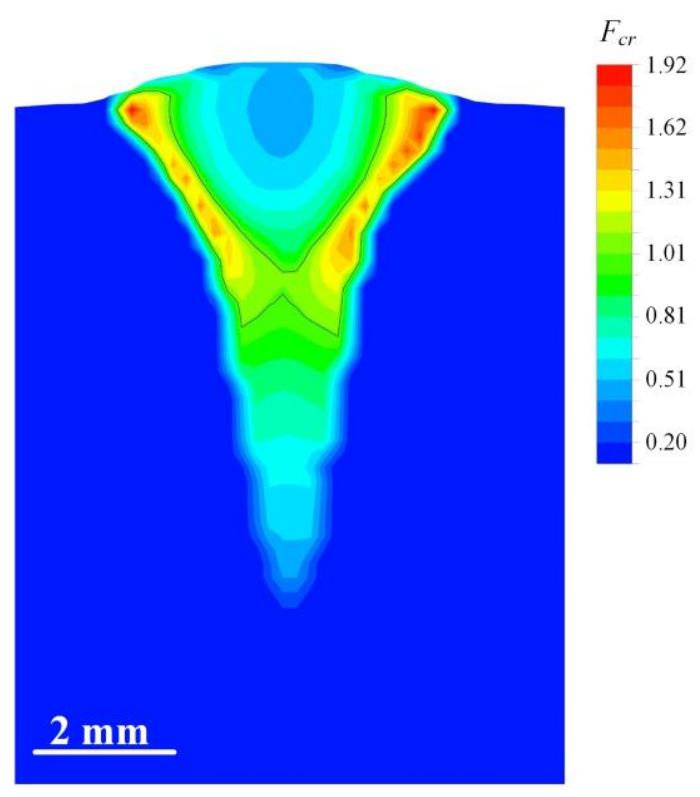

Fig. 16 The criterion factor of dendrite fragmentation by electromagnetic stirring on transverse section (The black line is the isoline of $F_{\mathrm{cr}}=1$ ).

\section{Conclusions}

The weld pool behavior and its direct role on determining the final microstructure in the wire feed laser beam welding with electromagnetic stirring (EMS-WFLBW) are studied through experiment and numerical simulation in this paper. The conclusions can be summarised as below:

(1) A heat transfer and fluid flow model coupled with element transport and magnetic induction is developed for EMS-WFLBW to calculate the MHD behavior, temperature and velocity profiles, 
solidification parameter, keyhole evolution and element distribution. The reasonability of the model is well tested against the experimental results.

(2) Under the magnetic field of $235 \mathrm{mT}$ and $3600 \mathrm{~Hz}$, a Lorentz force with a peak value of $1.9 \times 10^{6}$ $\mathrm{N} / \mathrm{m}^{3}$ is induced in the weld pool. The resultant electromagnetic stirring shows a significant impact on the thermal fluid flow.

(3) The added filler material is mixed more adequately in the weld pool because the downward and forward transfer along the longitudinal section is enhanced. The Ni content in the final weld can be predicted by the model.

(4) The grain size at the upper part of the weld is reduced significantly in the EMS-WFLBW. The refinement is rationalized quantitatively by the calculated solidification parameter and the criterion of dendrite fragmentation by electromagnetic stirring. It is found that the dendrite fragmentation, rather than the change in temperature gradient and solidification rate, dominates the grain refinement.

\section{Acknowledgement}

This work is funded by the Deutsche Forschungsgemeinschaft (DFG, German Research Foundation) - Project Nr. 416014189. The authors would like to appreciate Mr. Banglong Fu from HelmholtzZentrum Geesthacht for the EBSD analysis.

\section{References}

[1] Zhang K, Li D, Gui H, Li Z. Adaptive control for laser welding with filler wire of marine high strength steel with tight butt joints for large structures. J Manuf Process 2018; 36: 434-441.

[2] Tan T, Yung CS. Multi-scale modeling of solidification and microstructure development in laser keyhole welding process for austenitic stainless steel. Comput Mater Sci 2015; 98: 446-458.

[3] Davidson PA. An introduction to magnetohydrodynamics. 1st ed. Cambridge: Cambridge Press, 2001.

[4] Li XY, Fautrelle A, Gagnoud D, Du J, Wang J, Ren Z, Nguyen-Thi H, Mangelinck-Noel N. Effect of a weak transverse magnetic field on solidification structure during directional solidification. Acta Mater 2014; 64: 367-381.

[5] Kern M, Berger P, Huegel H. Magneto-fluid dynamic control of seam quality in $\mathrm{CO}_{2}$ laser beam welding. Weld J 2000; 79: 72-8.

[6] Avilov V, Fritzsche A, Bachmann M, Gumenyuk A, Rethmeier M. Full penetration laser beam welding of thick duplex steel plates with electromagnetic weld pool support. J Laser Appl 2016; 28 : 022420. 
[7] Fritzsche A, Hilgenberg K, Teichmann F, Pries H, Dilger K, Rethmeier M. Improved degassing in laser beam welding of aluminum die casting by an electromagnetic field. J Mater Process Technol 2018; 253: 51-6.

[8] Gatzen M. Influence of low-frequency magnetic fields during laser beam welding of aluminium with filler wire. Phys. Procedia 2012; 39: 59-66.

[9] Chen R, Jiang P, Shao X, Mi G, Wang C. Effect of static magnetic field on microstructures and mechanical properties of laser-MIG hybrid welding for 304 stainless steel. Int J Adv Manuf Technol 2017; 91: 3437-3447.

[10] Yan F, Wang X, Chai F, Ma H, Tian L, Du X, Wang W. Improvement of microstructure and performance for steel/Al welds produced by magnetic field assisted laser welding. Optics Laser Technol 2019; 113: 164-170.

[11] Rong Y, Xu J, Cao H, Zheng H, Huang Y, Zhang G. Influence of steady magnetic field on dynamic behavior mechanism in full penetration laser beam welding. J Manuf Process 2017; 26: 399406.

[12] Gatzen M, Tang Z, Vollertsen F, Mizutani M, Katayama S. X-ray investigation of melt flow behavior under magnetic stirring regime in laser beam welding of aluminum. J Laser Appl 2011; 23: 032002.

[13] Bachmann M, Avilov V, Gumenyuk A, Rethmeier M. Experimental and numerical investigation of an electromagnetic weld pool support system for high power laser beam welding of austenitic stainless steel. J Mater Process Technol 2015; 214: 578-591.

[14] Bachmann M, Kunze R, Avilov V, Rethmeier M. Finite element modeling of an alternating current electromagnetic weld pool support in full penetration laser beam welding of thick duplex stainless steel plates. J Laser Appl 2016: 28: 022404.

[15] Chen J, Wei Y, Zhan X, Gu C, Zhao X. Thermoelectric currents and thermoelectric-magnetic effects in full-penetration laser beam welding of aluminum alloy with magnetic field support. Int $\mathrm{J}$ Heat Mass Transf 2018; 127: 332-344.

[16] Gatzen M, Tang Z, Vollertsen F. Effect of electromagnetic stirring on the element distribution in laser beam welding of aluminium with filler wire. Phys Procedia 2011; 12: 56-65.

[17] Chen X, Luo M, Hu R, Li R, Liang L, Pang S. Thermo-electromagnetic effect on weld microstructure in magnetically assisted laser welding of austenite steel. J Manu Process 2019; 41: 111-118.

[18] Kawahito Y, Matsumoto N, Mizutani M, Katayama S. Characterization of plasma induced during high power fibre laser welding of stainless steel. Sci Technol Weld Join 2008; 13: 744-748 
[19] Hu R, Luo M, Liu T, Liang L, Huang A, Trushnikov D, Pang S. Thermal fluid dynamics of liquid bridge transfer in laser wire deposition 3D printing. Sci Technol Weld Join 2019; 24: 1-11.

[20] Ki H, Mazumder J, Mohanty PS. Modeling of laser keyhole welding: Part I Mathematical modeling, numerical methodology, role of recoil pressure, multiple reflections, and free surface evolution. Metall Mater Transact A 2002; 33: 1817-1830

[21] X Meng, G Qin, R Zong, Thermal behavior and fluid flow during humping formation in highspeed full penetration gas tungsten arc welding, Int J Therm Sci 134 (2018) 380-391

[22] Arata Y, Maruo H, Miyamoto I Nishio R. High Power $\mathrm{CO}_{2}$ Laser Welding of Thick Plate: Multipass Weding with Filler Wire (Welding Physics, Process \& Instrument). Transact JWRI 1986; 15: 199-206

[23] Salminen A. The filler wire--laser beam interaction during laser welding with low alloyed steel filler wire. Mechanika 2010; 4: 67-75

[24] Kawahito Y, Matsumoto N, Abe Y, Katayama S. Relationship of laser absorption to keyhole behavior in high power fiber laser welding of stainless steel and aluminum alloy. J Mater Process Technol 2011; 211: 1563-1568

[25] Lu F, Li X, Li Z, Tang X, Cui H. Formation and influence mechanism of keyhole-induced porosity in deep-penetration laser welding based on three-dimensional transient modeling, Int J Heat Mass Transf 2015; 90: 1143-1152

[26] Katayama S, Kawahito Y, Mizutani, M. Elucidation of laser welding phenomena and factors affecting weld penetration and welding defects. Phys Procedia 2010; 5: 9-17

[27] Hirano K, Fabbro R, Muller M. Experimental determination of temperature threshold for melt surface deformation during laser interaction on iron at atmospheric pressure. J Phys D: Appl Phys 2011; 44: 435402.

[28] Muhammad S, Han SW, Na SJ, Gumenyuk A, Rethmeier M. Study on the role of recondensation flux in high power laser welding by computational fluid dynamics simulations. J Laser Appl 2018; 30: 012013.

[29] Semak V, Matsunawa A. The role of recoil pressure in energy balance during laser materials processing. J Phys D: Appl Phys 1997; 30: 2541.

[30] Tan W, Shin, Y C. Analysis of multi-phase interaction and its effects on keyhole dynamics with a multi-physics numerical model. J Phys D: Appl Phys 2014; 47: 345501

[31] Cho WI, Na SJ, Thomy C, Vollertsen F. Numerical simulation of molten pool dynamics in high power disk laser welding. J Mater Process Technol 2012; 212: 262-275. 
[32] Su Y, Li Z, Mills KC. Equation to estimate the surface tensions of stainless steels. J Mater Sci 2005; 40: 2201-2205

[33] Peckner D, Bernstein I. Handbook of Stainless Steels. 1st ed. New York: McGraw-Hill Book Company, 1977.

[34] Mills KC. Recommended values of thermophysical properties for selected commercial alloys. 1st ed. Cambridge: Woodhead Publishing, 2002.

[35] Maglić KD, Perović NL, Stanimirović AM. Calorimetric and transport properties of Zicalloy 2, Zircalloy 4, and Inconel 625. Int J Thermophys 1994; 15: 741-755

[36] Ono Y, Matsumoto S. Diffusion of chromium, manganese, and nickel in molten iron. Transact Jpn Inst Met 1975; 16: 415-422

[37] Kawahito Y, Nakada K, Uemura Y, Mizutani M, Nishimoto K, Kawakami H, Katayama S. Relationship between melt flows based on three-dimensional X-ray transmission in situ observation and spatter reduction by angle of incidence and defocussing distance in high-power laser welding of stainless steel. Weld Int 2018; 32: 485-496.

[38] Wei HL, Elmer JW, DebRoy T. Crystal growth during keyhole mode laser welding. Acta Mater 2017; 133: 10-20.

[39] Liotti E, Lui A, Vincent R, Kumar S, Guo Z, Connolley T, Dolbnya IP, Hart M, Arnberg L, Mathiesen RH, Grant PS. A synchrotron X-ray radiography study of dendrite fragmentation induced by a pulsed electromagnetic field in an Al-15Cu alloy. Acta Mater 2014; 70: 228-239

[40] Campanella T, Charbon C, Rappaz M. Grain refinement induced by electromagnetic stirring: a dendrite fragmentation criterion. Metall Mater Transact A 2004; 35: 3201-3210.

[41] Mousavi MG, Hermans MJM, Richardson IU, Den Ouden G. Grain refinement due to grain detachment in electromagnetically stirred AA7020 welds. Sci Technol Weld Join 2003; 8: 309-312. 


\section{Figure caption}

Fig. 1 Experimental system: (a) schematic of EMS-WFLBW, (b) distribution of magnetic flux density. Fig. 2 Boundary conditions of simulation model

Fig. 3 Induced electric current density at longitudinal section

Fig. 4 Secondary magnetic field in the wed pool.

Fig. 5 Distribution of the Lorentz force in the weld pool: (a) $t_{0}$ (b) $t_{0}+1 / 4 \times$ magnetic field period Fig. 6 Calculated temperature profile and velocity field: (a) WFLBW, (b) EMS-WFLBW Fig. 7 Image of weld pool captured by high-speed camera

Fig. 8 Velocity magnitude at the longitudinal section: (a) WFLBW, (b) EMS-WFLBW Fig.9 Experimental and numerical fusion line shape: (a) WFLBW, (b) EMS-WFLBW Fig. 10 Calculated Ni distribution on transverse section: (a) WFLBW, (b) EMS-WFLBW

Fig. 11 Comparison of calculated and experimental Ni content along center line of transverse section: (a) WFLBW, (b) EMS-WFLBW

Fig. 12 Calculated 3D vector of temperature gradient ahead of the solidification front at $\mathrm{z}=9 \mathrm{~mm}$ and $\mathrm{z}=6 \mathrm{~mm}$ : (a) WFLBW, (b) EMS-WFLBW.

Fig. 13 Microstructure morphology at horizontal plane $\mathrm{z}=9 \mathrm{~mm}$ : (a) WFLBW, (b) EMS-WFLBW Fig. 14 EBSD maps at different positions of transverse section: (a), (c) and (e) from WFBLW, (b), (d) and (f) from EMS-WFLBW

Fig. 15 Solidification parameters on transverse section: (a) solidification rate, (b) temperature gradient

Fig. 16 The criterion factor of dendrite fragmentation by EMS on transverse section (The black line is the isoline of $F_{\mathrm{cr}}=1$ ). 


\section{Table caption}

Table 1 Nominal chemical composition of 304 steel and Inconel 625

Table 2 Nomenclature in the simulation model. 